\title{
ULTRACYTOCHEMICAL STUDIES ON THE EFFECTS OF THIAMINE AND THIAMINE TETRAHYDROFURFURYL DISULFIDE ON ACETYLCHOLINESTERASE ACTIVITY IN GUINEA PIG ATRIA
}

\author{
Kazuo Ogawa, Hiroshi Hirano, ${ }^{1}$ and Hideo ShinozaKI ${ }^{2}$ \\ ${ }^{1}$ Department of Anatomy, Kansai Medical University, Moriguchi, Osaka 570 \\ ${ }^{2}$ Biological Research Laboratories, Central Research Division, Takeda \\ Chemical Industries, Ltd., Yodogawa-ku, Osaka, Japan
}

(Received September 10, 1975)

\begin{abstract}
Summary As a result of histological and ultracytochemical investigations concerning the influence of thiamine and its disulfide derivative, thiamine tetrahydrofurfuryl disulfide (TTFD), on acetylcholinesterase (AChE) in extirpated guinea pig atria, it was found that there was a clear increase in the AChE activity by $10^{-4} \mathrm{M}$ TTFD, a weak increase with $10^{-5} \mathrm{M}$ and an extremely weak increase, about the same as that in only the nutrient (Locke's solution), with $5 \times 10^{-4} \mathrm{M}$. However, with $10^{-4} \mathrm{M}$ of thiamine there was a tendency for the activity to be the same degree as with Locke's solution alone or be even inhibited at times.
\end{abstract}

According to NAKAZAWA et al. (9) in 1965, the unsymmetrical disulfide type thiamine derivative, TTFD, and its homologues exert a positive inotropic action (action to increase the myocardial contraction power) on extirpated guinea pig atria. This action gained considerable attention as a pharmacological action with no relation to the coenzyme action of thiamine cocarboxylase and it was widely studied. Considerable knowledge was gained concerning the mechanism of this action but there are still points that are not clear. If there was any correlation between this positive inotropic action and the increase in the AChE activity in guinea pig atria by TTFD, this could probably provide an important information about the mechanism of action in vivo of thiamine and thiamine derivatives.

\section{MATERIALS AND METHODS}

Extirpated guinea pig atria. The extirpated atria of normal adult male guinea

1 小川和朗, 平野 寛, ${ }^{2}$ 篠崎英男 
pig weighing $250-350 \mathrm{~g}$ were kept at $30-31{ }^{\circ} \mathrm{C}$ in oxygen saturated Locke's solution (1). The following experiments were started one hour after specimens were set in a Magmus device.

Addition of thiamine and TTFD. $10^{-4} \mathrm{M}$ (final concentration) of thiamine and $10^{-4}, 5 \times 10^{-4}$ or $10^{-5} \mathrm{M}$ (final concentration) of TTFD were added to the oxygen saturated Locke's solution and after rhythmic movement continued for one hour, the AChE activity in the atria was investigated.

Detection of the AChE activity. Directly after the above treatment, the extirpated atria were placed for $2-3 \mathrm{hr}$ at $0-4{ }^{\circ} \mathrm{C}$ in a mixture of $2 \%$ glutaraldehyde (dissolved in $0.1 \mathrm{M}$ cacodylate buffer, $\mathrm{pH}$ 7.4) or Karnovsky's aldehyde mixture (2). After washing overnight in a $0.1 \mathrm{M}$ cacodylate buffer, $\mathrm{pH} 7.4$, frozen or nonfrozen slices, $20-40 \mu$ thick, were prepared and incubated for $20-40 \mathrm{~min}$ at $4^{\circ} \mathrm{C}$ in the incubation medium for the demonstration of the AChE activity (KARNOVSKY, 1964 (3), copper ferrocyanide method, $\mathrm{pH}$ 6.0). Acetylthiocholine iodide was used as the substrate for the detection of AChE activity. As the control media, the medium without substrate, medium containing butyrylthiocholine inlieu of acetylthiocholine iodide and medium containing eserine $\left(10^{-4}-10^{-5} \mathrm{M}\right)$, the AChE activity inhibitor, were used.

After incubation, the specimens were again fixed in $1 \%$ buffered osmium tetroxide, dehydrated with ethanol and embedded in Epon. Ultra-thin sections were then prepared and stained with uranyl and lead. They were examined with a JEM-7 electron microscope.

Part of the specimens were also observed with a light microscopic after incubation.

\section{RESULTS AND DISCUSSION}

The AChE activity is positive in nerve elements which are closely related positionally to the impulse-conducting system $(4,5)$. In other words, it is positive in membranes corresponding to spaces between axons and Schwann cells, spaces between axons, spaces between axons and the specific muscles, and corresponding membranes. No activity was found in medullated nerve fibers.

No reaction products showing the AChE activity were found when the specimens were incubated in the substrate-free medium or in the medium containing butyrylthiocholine iodide as substrate.

The enzyme activity was partially inhibited by $10^{-5} \mathrm{M}$ of eserine and completely inhibited by $10^{-4} \mathrm{M}$.

When the AChE activity is compared among atria subjected to the rhythmic movement in Locke's solution containing TTFD, atria subjected to such movement only in Locke's solution and atria subjected to such movement in Locke's solution containing thiamine, the enzymatic activity was very weak in atria in Locke's solution only and almost no activity was observed (Fig. 1). In $10^{-4} \mathrm{M}$ 
of thiamine, the activity was almost the same as that in Locke's solution only or it sometimes tended to be inhibited (Fig. 2). However, in $10^{-4} \mathrm{M}$ of TTFD, there was a clear increase in the AChE activity. Figs. 1-4 show the electron microscopic examinations of these findings. As can be seen in the latter figures, there were almost no reaction products showing the AChE activity in atria in Locke's solution only (Figs. 5-7), but reaction products showing AChE activity were found in nerve elements in atria in Locke's solution containing $10^{-4} \mathrm{M}$ of TTFD (Figs. 8-12). In all cases, fine structures or organelles such as the mitochondria in the extirpated atria showed no damage and were exactly the same as those in normal atria.

Although the details have not yet been published (6), when thiamine (15 mg or $50 \mathrm{mg} / \mathrm{kg}$ of body weight) or TTFD $(10 \mathrm{mg}, 15 \mathrm{mg}, 50 \mathrm{mg}$ or $100 \mathrm{mg} / \mathrm{kg}$ of body weight) was injected intraperitoneally once a day for 10 consecutive days in adult male guinea pigs (dissolved in glucose. Controls were injected with the same amount of glucose only for the same periods), and three hours after the final injection, the guinea pigs were sacrificed, and the AChE activity was detected in the atria in the same way as mentioned previously, it was found that the AChE activity was the same as in the controls or slightly suppressed when $15 \mathrm{mg}$ or $50 \mathrm{mg} / \mathrm{kg}$ of thiamine was given, while with $50 \mathrm{mg} / \mathrm{kg}$ of TTFD, there was a clear increase in the AChE activity and a slight increase with $15 \mathrm{mg} / \mathrm{kg}$ of TTFD. The AChE activity was the same as in the controls in guinea pigs given $10 \mathrm{mg} / \mathrm{kg}$ of TTFD and there was a weak suppression of the activity when $100 \mathrm{mg} / \mathrm{kg}$ of TTFD was given.

When the relation between the increase in heart contraction power by TTFD shown on kymographs and the increase in the AChE activity histochemically detected was correlated, there seems to exist a parallel relation between the two, and it is postulated that investigations of the details of this correlation, the relation of the present findings to the choline acetylase activity $(7,8)$ etc., will be of great interest in elucidating the in vivo action of thiamine and its derivatives.

\section{REFERENCES}

1) Sinozaki, H., Morita, M., Sugimoto, J., and Nagata, H., Vitamins (in Japanese), 44, 37 (1971).

2) Karnovsky, M. J., J. Cell Biol., 27, 137A (1965).

3) Karnovsky, M. J., J. Cell Biol., 23, 217 (1964).

4) Hirano, H. and Ogawa, K., Histochem., 17, 49 (1969).

5) Hirano, H. and Ogawa, K., J. Electron Micros., 16, 313 (1967).

6) Ogawa, K., Hirano, H., Mayahara, H., Vitamins (in Japanese), 37, 222 (1968).

7) Ogawa, K., Ago, Y., and Tanaka, T., U.S. Japan Seminar, Monterey, U.S.A., October 3-5, 1974.

8) Ago, Y. and Ogawa, K., 8th Int. Congr. Electron Micros., Canberra, Australia, August 25-31, 1974.

9) NaKaZawa, Y. and Ueno, A., Japan J. Pharmacol., 15. 10 (1965). 

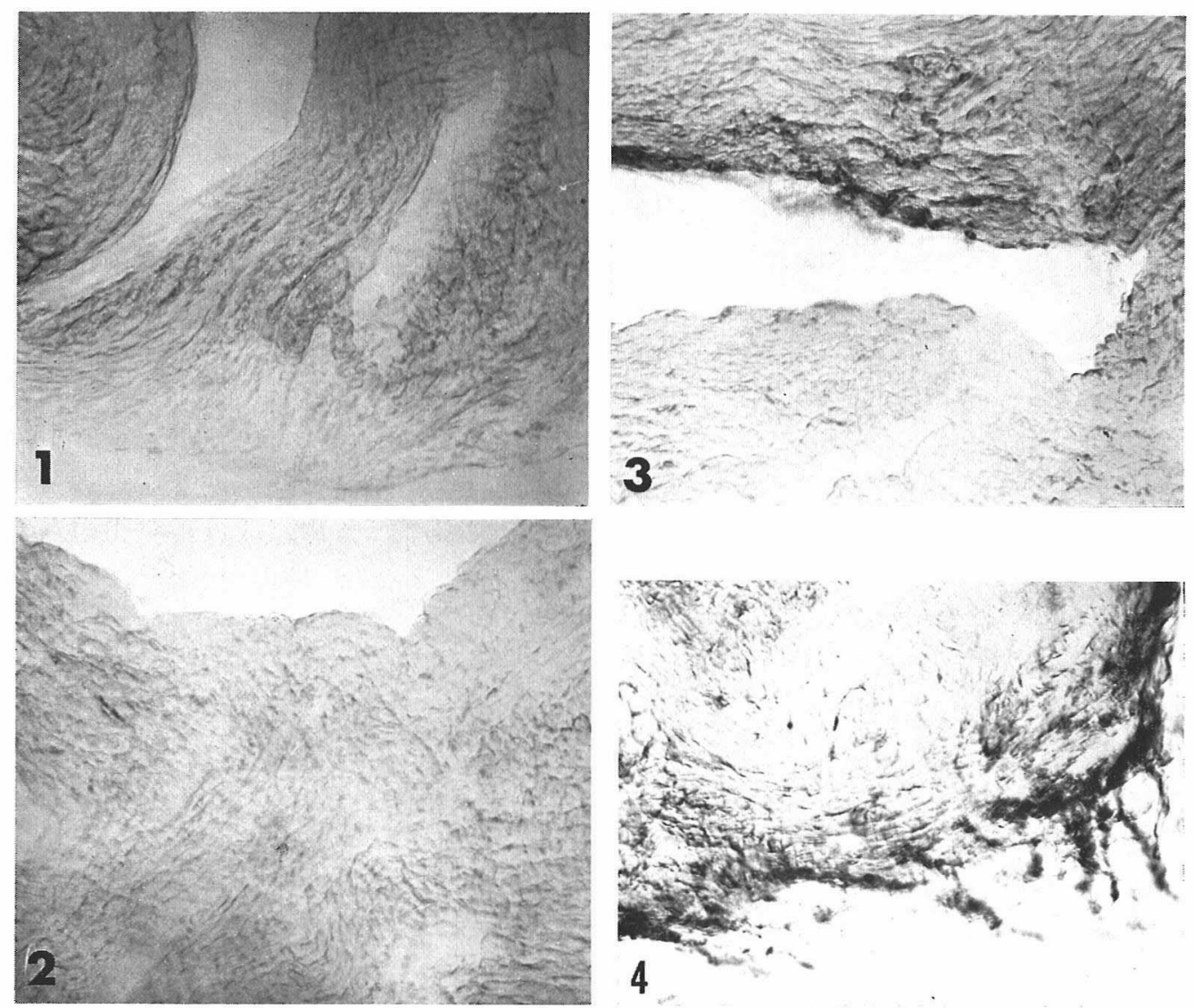

Figs. 1-12. Extirpated guinea pig atria. Detection of the acetylcholinesterase (AChE) activity by the copper ferrocyanide method.

Figs. 1-4. Microscopic findings.

Figs. 5-12. Electron microscopic findings.

Fig. 1. Atria subjected to rhythmic movement in oxygen saturated Locke's solution for one hour. The AChE activity was extremely weak and almost none. $\quad \times 260$

Fig. 2. Atria subjected to rhythmic movement in oxygen saturated Locke's solution containing thiamine (final concentration of $10^{-4} \mathrm{M}$ ) for one hour. Findings were almost the same as in Fig. $1 . \quad \times 260$

Figs. 3 and 4. Atria subjected to rhythmic movement in oxygen saturated Locke's solution containing TTFD (final concentration of $10^{-4} \mathrm{M}$ ) for one hour. There was a clear increase in the AChE activity. $\quad \times 260$ for both Figs. 3 and 4 .

Figs. 5-7. Atria subjected to rhythmic movement for one hour in oxygen saturated Locke's solution. The fine structure is well preserved, but no reaction products showing the AChE activity were found. Fig. 5, ×35,000, Fig. 6, $\times 23,000$ and Fig. 7, $\times 28,000$.

Figs. 8-12. Atria subjected to rhythmic movement for one hour in oxygen saturated Locke's solution containing TTFD (final concentration of $10^{-4} \mathrm{M}$ ). The activity was found in the axonal membrane, the corresponding Schwann cell membrane and spaces between them. Figs. 8-10, ×35,000; Fig. 11, $\times 60,000$ and Fig. 12, $\times 35,000$. 

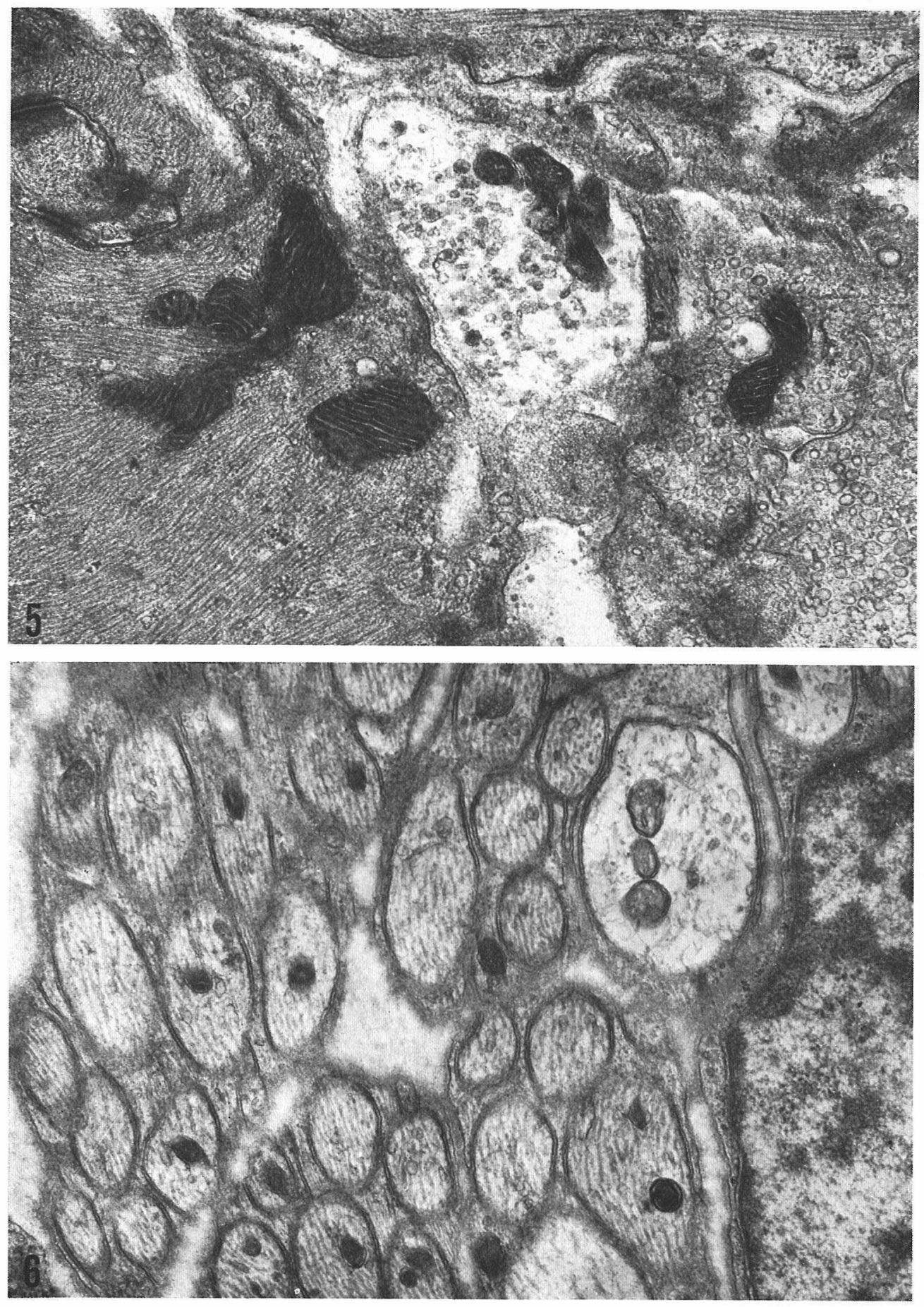

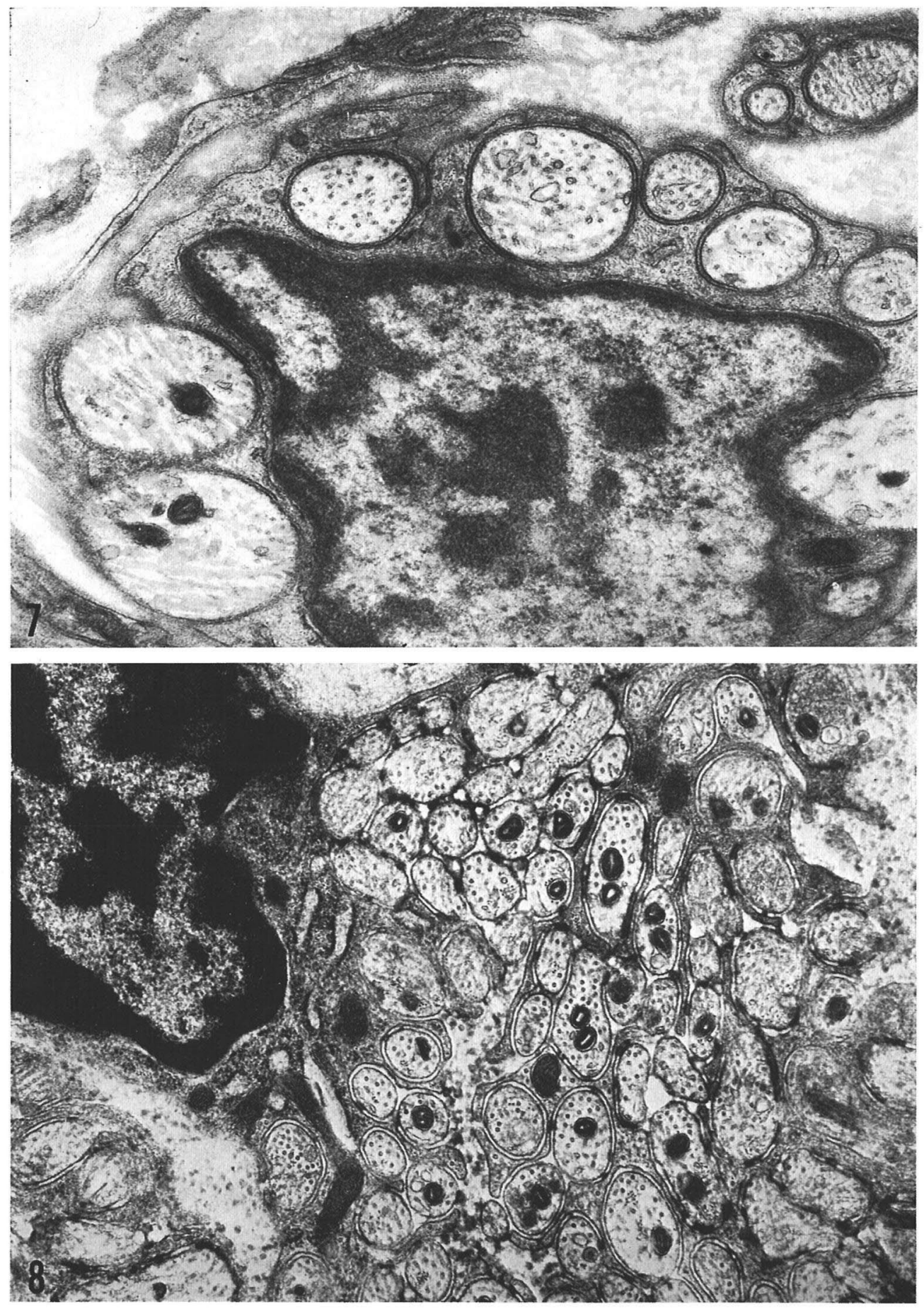

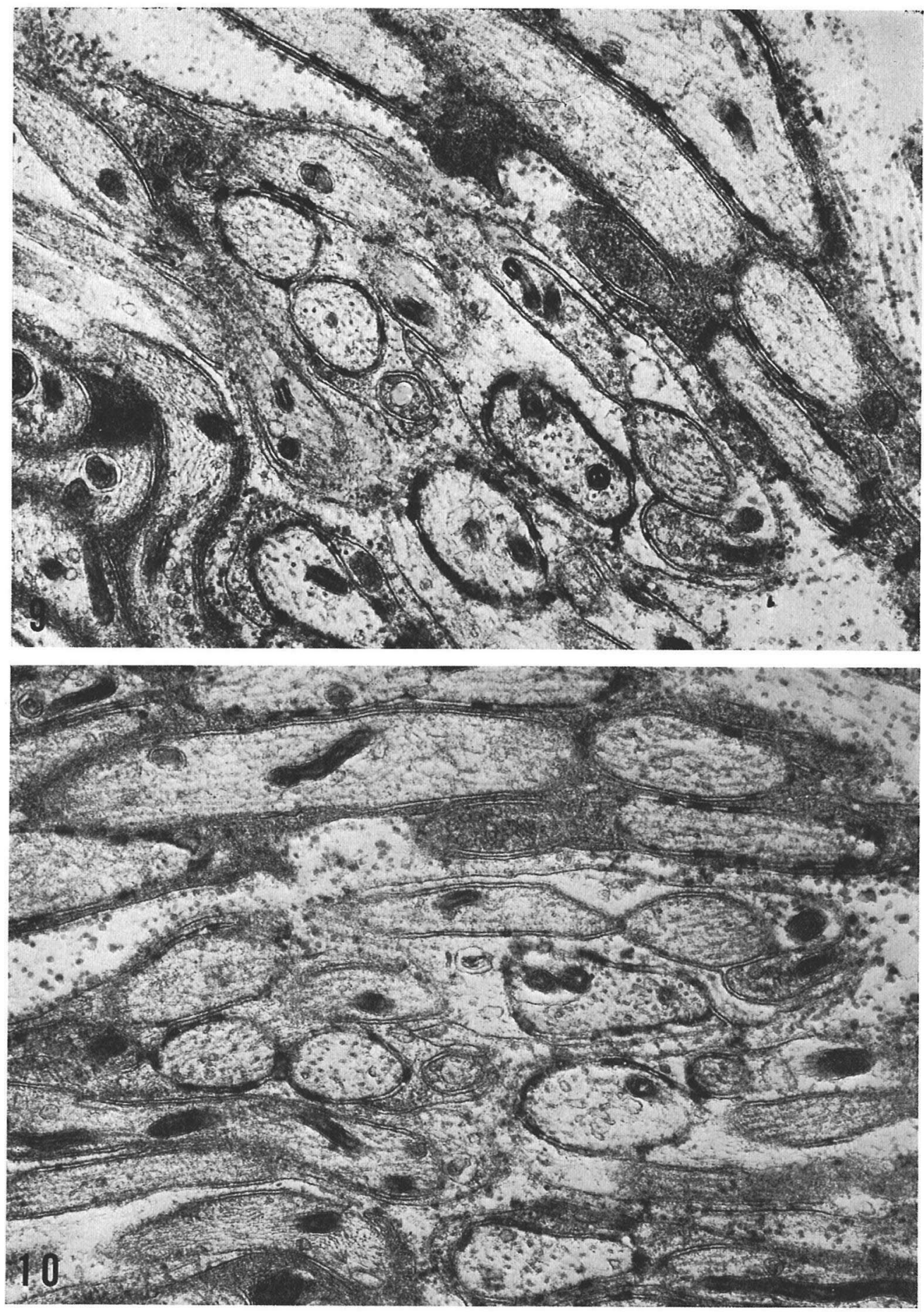


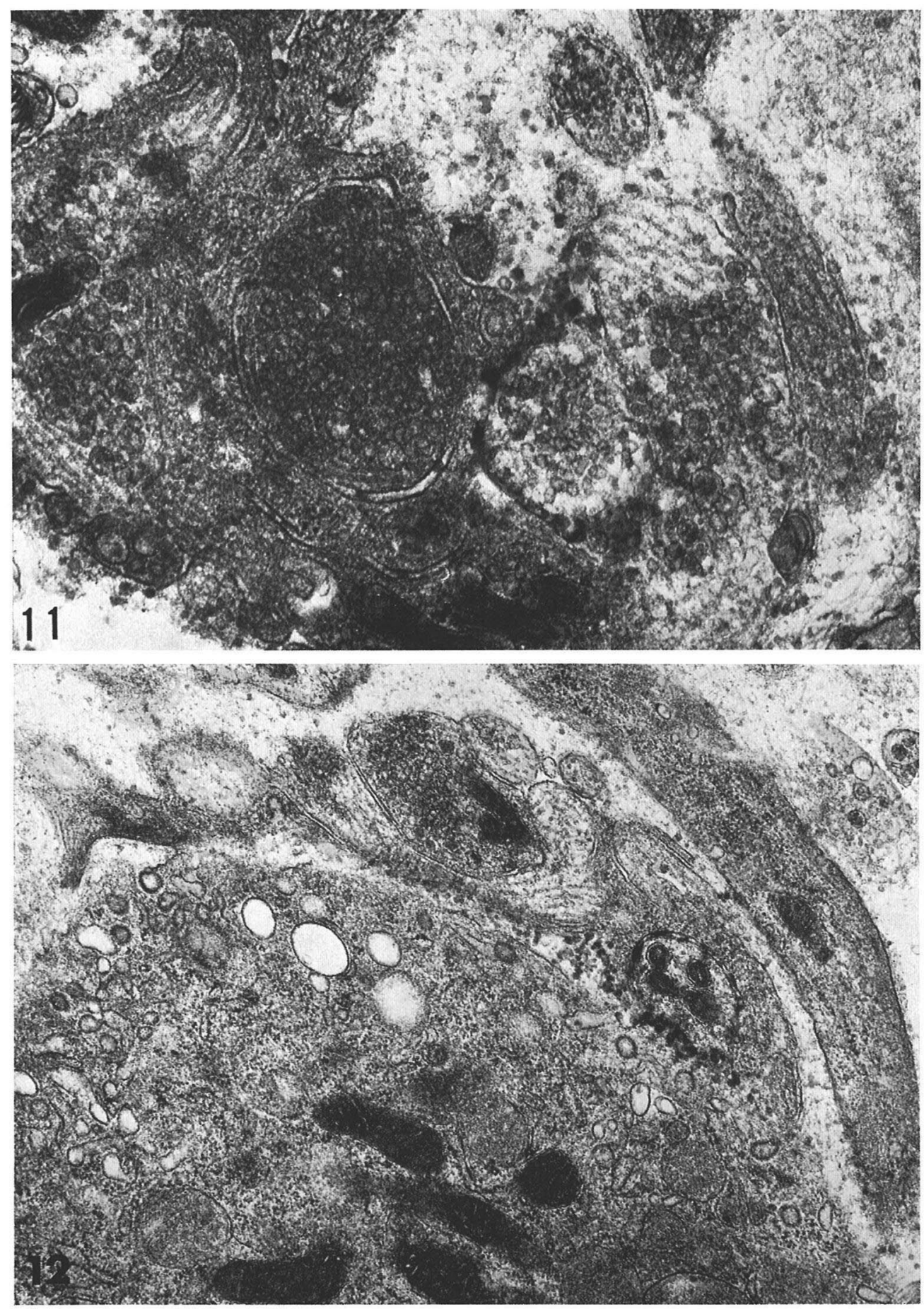

